\title{
Nematode-Trapping Fungi in Organic and Conventional Cropping Systems
}

\author{
B. A. Jaffee, H. Ferris, and K. M. Scow
}

First and second authors: Department of Nematology; third author: Department of Land, Air, and Water Resources, University of California at Davis, 1 Shields Ave., Davis 95616-8668.

Accepted for publication 13 January 1998.

\begin{abstract}
Jaffee, B. A., Ferris, H., and Scow, K. M. 1998. Nematode-trapping fungi in organic and conventional cropping systems. Phytopathology 88:344350 .

Nematode-trapping fungi, nematodes, and microbial biomass were quantified in conventionally and organically managed field plots in the Sustainable Agriculture Farming Systems Project at the University of California at Davis. There were four replicate plots ( 0.135 ha per plot) for each management system, and plots were sampled three times each year for 2 years. The hypothesis that nematode-trapping fungi would be more abundant in organically managed plots was partially supported: the number of species of nematode-trapping fungi was slightly but significantly greater in organic than in conventional plots, two species (Arthrobotrys dactyloides and Nematoctonus leiosporus) were detected more
\end{abstract}

ABSTRACT frequently in organic plots, and the population densities of A. dactyloides and $N$. leiosporus were greater in organic than in conventional plots. Two other species (A. haptotyla and A. thaumasia), however, tended to be more numerous in conventional than in organic plots, and the total density of nematode-trapping fungi was similar in organic and conventional plots. Bacterivorous nematodes were more abundant and microbial biomass (substrate-induced respiration) was greater in organic than in conventional plots. Suppression of the root-knot nematode Meloidogyne javanica, as measured in a bioassay, was not related to management system or population density of nematode-trapping fungi but was positively related to microbial biomass.

Additional keywords: nematophagous fungi, plant-parasitic nematodes.
Organic amendments to soil are thought to stimulate nematodetrapping fungi (12), but these fungi are difficult to quantify (10), and the data, especially field data, are minimal. In several laboratory, greenhouse, and microplot studies, stimulation of nematode-trapping fungi was not measured but was inferred or suggested when organic amendments suppressed plant-parasitic nematodes or increased plant growth (19,32-34). In other laboratory studies, nematode-trapping or closely related endoparasitic fungi were quantified and were stimulated $(3,6,14,43)$ or suppressed $(21)$ by organic amendments.

In agricultural fields, the effect of organic amendments on nematode-trapping or endoparasitic fungi has been quantified only four times. Although useful, these field studies have important limitations. Dackman et al. (11) found greater numbers of nematode-trapping fungi in two plots treated with manure than in one plot treated with inorganic fertilizer, but plots were not replicated and fungi were not identified to species. Van den Boogert et al. (43) found that population densities of nematode-trapping fungi were 10 times greater in a wheat field with high organic matter content than in a barley field with low organic matter content; again, fields were not replicated. Jaffee et al. (21) reported that composted chicken manure suppressed the parasitic activity of the fungus Hirsutella rhossiliensis in a peach orchard; however, the experiment was short (6 months), and the amendment may have generated unusually large quantities of ammonia. Persmark (35) found no differences in the number of nematode-trapping fungi among 10 pairs of organically and conventionally managed fields, but the fields apparently did not differ greatly in organic matter inputs; moreover, the paired fields were near each other but were not true replicates.

Corresponding author: B. A. Jaffee; E-mail address: bajaffee@ucdavis.edu

Publication no. P-1998-0213-01R

(C) 1998 The American Phytopathological Society
The Sustainable Agriculture Farming Systems (SAFS) Project at the University of California at Davis contains replicated plots that have received substantially different amounts of organic amendments since $1988(39,40)$. According to previous studies at SAFS, microbial biomass and activity (18) and number of bacterivorous nematodes (15) are greater in the organic plots than in the conventional plots during the tomato growing season. The current study tests three hypotheses: population densities and number of species of nematode-trapping fungi are greater in organically managed versus conventionally managed soils; organically managed soils are more suppressive to root-knot nematodes than are conventionally managed soils; and suppressiveness correlates with population densities of nematode-trapping fungi.

\section{MATERIAL AND METHODS}

Plots and rotations. The SAFS Project was started in 1988 and involves 11.3 contiguous hectares (class I Yolo silty loam) divided into replicated 0.135 -ha plots, which have been farmed according to four management systems. The two farming systems considered in this paper are the conventional 4-year system and the organic 4year system. Detailed descriptions of these systems have been published (30,38-40).

In the eight plots considered in this study, 1992 values for $\mathrm{pH}$ and soil organic matter were 7.3 versus 7.1 and 1.60 versus $1.48 \%$ in organic versus conventional plots, respectively (38). The experimental design was a split plot (four farming systems within each of four replicate blocks). Plots were $67 \times 18 \mathrm{~m}$ and had been in a 4-year rotation since the start of the project (Table 1).

Although the two systems differ in management of foliar pests and weeds $(30,39,40)$, the major differences affecting soil biology probably reflect inputs of organic matter and growth of a cover crop (18). Conventional plots receive inorganic fertilizer every year, a cover crop is only grown every fourth year (Table 1), and the cover crop is harvested rather than incorporated. Organic mat- 
ter inputs in conventional plots, therefore, are limited to crop residues. In contrast, organic plots receive composted manure every other year, and a cover crop is grown and incorporated into the organic plots every year: the cover crop was incorporated on 10 July 1995 and 29 April 1996, and the composted manure $(2.92 \times$ $10^{2} \mathrm{~kg} / \mathrm{ha}$, containing $1.34 \times 10^{2} \mathrm{~kg}$ of nitrogen per ha) was added and incorporated on 10 April 1996.

Sample collection. On each sampling date, we collected 50 cores per plot with a tube ( $2 \mathrm{~cm}$ diameter, $15 \mathrm{~cm}$ deep); based on a recent report (36), a sampling depth of $15 \mathrm{~cm}$ is appropriate for nematode-trapping fungi. Core location was random, but we took samples from the planting bed near roots if a crop was present, because we assumed that nematodes and nematode-trapping fungi were more abundant in the rhizosphere than in bulk soil; a recent paper confirmed this assumption (37). When a crop was not present, proximity of cores to the roots of the previous crop was unknown (the planting beds and furrows had been removed by cultivation). Between plots, the sampling tubes were washed in water, sprayed with $70 \%$ ethanol, and dried. Soil (2.5 to 3.0 liters per plot) was sieved through 5-mm hardware cloth, which was washed, sprayed with $70 \%$ ethanol, and heated to $100^{\circ} \mathrm{C}$ for $6 \mathrm{~min}$ between samples. Soil moisture ( $\mathrm{g}$ of water per $100 \mathrm{~g}$ of soil) was determined gravimetrically. Soils were stored at $10^{\circ} \mathrm{C}$ for fewer than 10 days before determination of nematode-trapping fungi and nematode suppressiveness. Soils were stored for fewer than 30 days before other determinations were made.

Plots were sampled three times each year: before the main crop was planted (bean in 1995 and tomato in 1996), during midseason of the main crop, and after the main crop was harvested. The sampling dates were 11 April, 14 August, and 7 November in 1995 and 29 March, 24 June, and 30 September in 1996.

Nematode-trapping fungi. Nematode-trapping fungi were quantified by dilution plating and most probable number procedures $(13,23,28)$. Soil from each sample (100 g, dry weight equivalent) was placed in a sterile $250-\mathrm{ml}$ flask, and the volume was increased to $200 \mathrm{ml}$ with sterile distilled water. The flask was shaken vigorously for $7 \mathrm{~min}$, which was sufficient to break apart all soil peds. A fivefold dilution series was prepared, and each of five petri plates, containing quarter-strength cornmeal agar (CMA/4), received $0.1 \mathrm{ml}$ of each of three dilutions. Thus, $0.05,0.01$, or $0.002 \mathrm{~g}$ of soil was added per plate. The $0.1-\mathrm{ml}$ aliquots were added in five drops down the center of each plate and were not spread. To increase the probability of detecting nematode-trapping fungi, bait nematodes (1,000 Steinernema glaseri) were added to each plate in $0.1 \mathrm{ml}$ of water. Infective juveniles of $S$. glaseri were obtained from infected Galleria mellonella (27) and stored at $10^{\circ} \mathrm{C}$ for fewer than 45 days before addition to plates. After aliquots and nematodes were added, the plates were left uncovered until excess water was absorbed or evaporated. After 3 weeks at $22 \pm 2{ }^{\circ} \mathrm{C}$, plates were examined with a dissecting microscope. Nematodetrapping fungi were identified to species based on the characteristics of trap, conidiophore, and conidium, using a key (9) and original descriptions as needed. Plates were scored for presence and absence of fungi, and the number of propagules per gram of soil was estimated by a most probable number program (28).

Given the levels of dilution and replication, the theoretical lower limit of detection on dilution plates was 4.0 propagules per $g$ of soil (one of five plates positive in the most concentrated dilution and all other plates negative). To detect fungi at densities less than 4.0 propagules per $\mathrm{g}$ of soil, additional soil (2.0 g, dry weight equivalent) from each sample was added to sprinkle plates (23) made with CMA/4 (five plates per sample). These were baited with $S$. glaseri and handled and assessed identically to the soil dilution plates. The theoretical lower and upper detection limits of the sprinkle plates were 0.1 and 0.9 propagules per $g$ of soil (one and four positive plates of five total, respectively); one cannot estimate density when all plates are positive or negative $(28,45)$. Soil dilution and sprinkle plates were prepared within 7 days of sampling.
According to Woomer (45), when a dilution series produces a small or large number of positives across all levels of dilutions, new dilutions should be prepared so the most concentrated provides all positives and the least concentrated provides all negatives. However, dilutions cannot be more concentrated than $0.5 \mathrm{~g}$ of soil per ml, because they will not flow properly through a pipette and they tend to provide false negatives (37; B. A. Jaffee, unpublished data). We, therefore, used data from dilution series with few positive plates.

Nematodes. Nematodes were extracted from soil (100 g of soil per sample, dry weight equivalent) by elutriation and sugar-centrifugation $(4,26)$. Nematodes were counted and identified to trophic group and genus (15).

Microbial biomass. General microbial biomass was determined by substrate-induced respiration by procedures described by West and Sparling (44). Briefly, soil (5 g) was or was not amended with glucose $(200 \mu \mathrm{g} / \mathrm{g}$ of soil). After $2 \mathrm{~h}$ at room temperature, headspace $\mathrm{CO}_{2}$ was measured. Noninduced respiration is the head-space $\mathrm{CO}_{2}$ in soil without glucose amendment. Substrate-induced respiration is the difference in head-space $\mathrm{CO}_{2}$ in soil with and without glucose amendment.

Bioassay for nematode suppression. To measure suppression of nematodes by other organisms (natural enemies) in the soils, we compared activity of an assay nematode (the root-knot nematode Meloidogyne javanica) in heat-treated soil (nematode enemies were absent) and nonheat-treated soil (nematode enemies were present) as follows. Soil from each sample was heated to $60^{\circ} \mathrm{C}$ for $2 \mathrm{~h}$ or was nonheated. The heat treatment eliminated nematodetrapping fungi (23) and virtually all soil invertebrates (B. A. Jaffee, unpublished data). After cooling, the heat-treated soil was placed in a plastic bag and left exposed to the air (to allow $\mathrm{NH}_{3}$ to escape) for $24 \mathrm{~h}$ before sealing. The water content of all samples (heated and nonheated) was adjusted to the highest water content in the eight nonheat-treated samples by mixing the appropriate volume of distilled water into the soil.

Heated soil from each sample was placed in two polystyrene cups, and nonheated soil was placed in four cups $\left(100 \mathrm{~cm}^{3}\right.$ of soil per cup). Cups were covered with aluminum foil and placed in a moisture chamber (transparent plastic box with moist paper towels) at $20^{\circ} \mathrm{C}$ without light. After 10 days, any weed seedlings were removed. After 14 days, $\approx 750$ second-stage juveniles of $M$. javanica were added to the two cups containing heated soil and to two of the four cups containing nonheated soil. The cups receiving $M$. javanica provided information on suppression of $M$. javanica, whereas those not receiving $M$. javanica provided information on endoparasitic nematodes naturally present (resident) in the soil. $M$. javanica were obtained from hydroponic cultures (29) and added in $3.0 \mathrm{ml}$ of $4.5 \mathrm{mM} \mathrm{KCl}$ to the soil surface; the two cups of nonheated soil receiving no $M$. javanica received $3.0 \mathrm{ml}$ of $4.5 \mathrm{mM}$ $\mathrm{KCl}$. The cups were covered and returned to the moisture chamber at $20^{\circ} \mathrm{C}$. After $66 \mathrm{~h}$, covers were removed, six germinated cabbage seeds (Brassica oleraceae 'Grand Slam') were planted in each cup, and cups in moisture chambers were placed under fluorescent lights at $20^{\circ} \mathrm{C}$. After 5 days, roots were removed from soil, measured, stained, and cleared (5). Nematodes within roots were counted.

Suppression was calculated as suppression $=(1-a / b) \times 100$, where $a$ and $b$ were the number of assay nematodes in roots growing in nonheated and heated soil, respectively. To determine the number of

TABLE 1. Rotations in conventional and organic plots

\begin{tabular}{|c|c|c|c|c|c|}
\hline \multirow[b]{2}{*}{ System } & \multirow[b]{2}{*}{ Season } & \multicolumn{4}{|c|}{ Crop } \\
\hline & & 1993 & 1994 & 1995 & 1996 \\
\hline Conventional & Winter & Fallow & Fallow & Wheat & Fallow \\
\hline Conventional & Summer & Safflower & Corn & Bean & Tomato \\
\hline Organic & Winter & Vetch & Vetch & Oat/vetch & Vetch \\
\hline Organic & Summer & Safflower & Corn & Bean & Tomato \\
\hline
\end{tabular}


assay $M$. javanica in roots, we subtracted the number of Meloidogyne sp. in roots growing in soil without assay nematodes from the number in roots growing in soil with assay nematodes; this correction was minor, because the soil contained few resident Meloidogyne sp. (discussed below). Before analysis, data from the two cups per treatment were averaged to obtain one value per replicate plot.

Statistical analysis. SAS release 6.12 (SAS Institute, Inc., Cary, NC) was used throughout. Repeated measures analysis of variance was used to determine whether residuals for quantitative data were serially correlated and, hence, whether pseudoreplication was a problem. Population densities of fungi and nematodes were transformed $(\log x+1)$ before analysis; the suppression data were not transformed, because some values were negative. Quantitative data were subjected to an analysis of variance, and significance was determined at $P<0.05$; the independent variables in the model were management, block, management $\times$ block, date, and management $\times$ date; all independent variables were treated as categorical effects. Data were analyzed as a split plot in time, with management as the main plot effect and date as the subplot effect. Because the two systems were managed differently, at any sampling time the organic and conventional plots differed in plant age, soil moisture content, time since last cultivation, etc. Our analyses, therefore, emphasized differences across sampling dates rather than within sampling dates.

The data on fungus frequency (presence or absence) were subjected to logistic regression analysis (SAS GENMOD procedure) to test the effect of management; date effects were suppressed to achieve model convergence. The potential for pseudoreplication in this regression analysis was addressed by comparing the proportion of positive responses in a plot and between management systems, using Mann Whitney tests.

Finally, we determined whether suppression of the root-knot nematode $M$. javanica was correlated with fungus population density or substrate-induced respiration (SAS GLM procedure).

TABLE 2. Nematode-trapping fungi in Sustainable Agriculture Farming System Project (University of California, Davis) plots

\begin{tabular}{ll}
\hline Fungus & \multicolumn{1}{c}{ Trap } \\
\hline Arthrobotrys dactyloides & Constricting rings \\
A. haptotyla & Adhesive knobs \\
A. oligospora & Adhesive networks \\
A. superba & Adhesive networks \\
A. thaumasia & Adhesive networks \\
Meristacrum sp. $^{\text {a }}$ & Adhesive spores \\
Monacrosporium eudermatum $_{\text {Nematoctonus leiosporus }}^{\text {a }}$ & Adhesive networks \\
Stylopage sp. & Adhesive glandular cells \\
\hline
\end{tabular}

${ }^{a}$ Sometimes considered an endoparasitic rather than a nematode-trapping fungus.

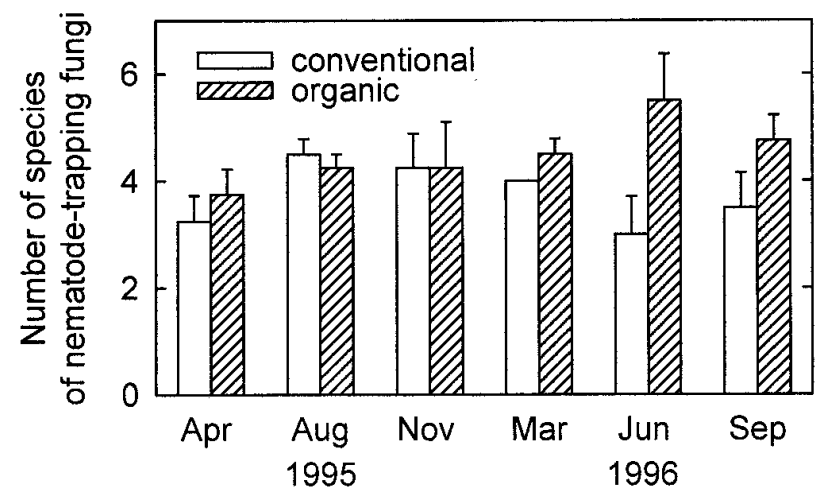

Fig. 1. Number of species of nematode-trapping fungi detected per plot in conventional and organic plots. Values are means plus the standard error of four replicate plots. Approximately $10 \mathrm{~g}$ of soil was processed per replicate.

\section{RESULTS}

For the quantitative data, an analysis of the residuals from the repeated measures analysis failed to detect serial correlation. Therefore, the effect of management could be examined over time with minimal danger of pseudoreplication. Block effects were not significant, indicating that spatial variation was small.

Number of species of nematode-trapping fungi and frequency of detection. Nine species of nematode-trapping fungi were found (Table 2). Meristacrum sp. and N. leiosporus usually are considered endoparasitic rather than trapping fungi, but the distinction between endoparasitic and trapping fungi is not clear cut (1). Moreover, the population densities of these two species were small (usually less than one propagule per gram of soil) and much less than those of the other fungi. To simplify data presentation, we treat Meristacrum sp. and $N$. leiosporus as trapping fungi in this paper.

Although the difference was not great or apparent at every date, more $(P=0.01)$ species of nematode-trapping fungi were found in the organic than in the conventional plots (Fig. 1). Based on both logistic regression and Mann Whitney tests, A. dactyloides and $N$. leiosporus were detected more often $(P<0.05)$ in organic than in conventional plots, whereas the opposite was true for A. thaumasia (Fig. 2). A. haptotyla tended to be detected less frequently in

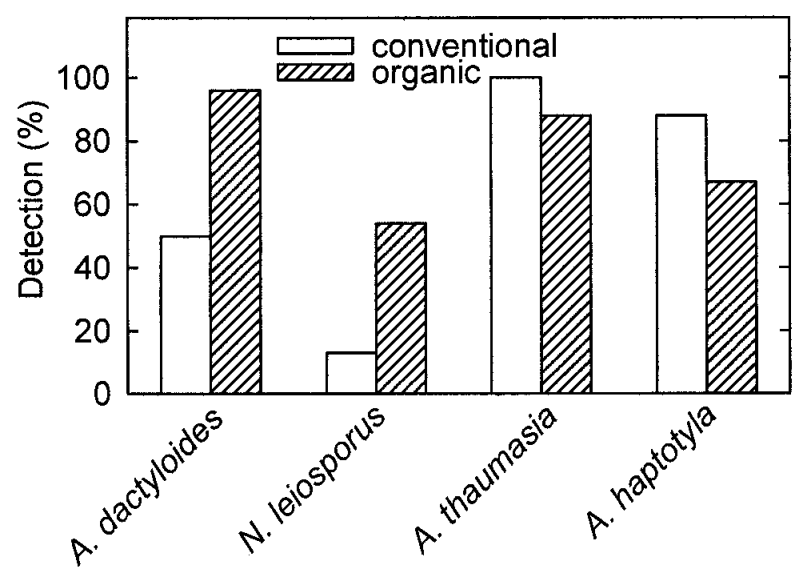

Fig. 2. Detection of four nematode-trapping fungi in conventional and organic plots. Arthrobotrys dactyloides, Nematoctonus leiosporus, A. thaumasia, and A. haptotyla were the most common fungi. Detection indicates the number of positive samples divided by 24 total samples (6 sample dates $\times 4$ replicate plots) $\times 100$.

TABLE 3. Trophic groups and taxa of nematodes extracted from soil

\begin{tabular}{llll}
\hline Bacterivore & Fungivore & Omnivore & Plant parasite \\
\hline $\begin{array}{l}\text { Acrobeles } \\
\text { Acrobeloides }\end{array} \quad$ Aphelenchoides & Aporcelaimus & Filenchus \\
A. buetschlii & Aphelenchus & Dipthorophora & Meloidogyne \\
A. tricornis & & Discolaimus & Paratylenchus \\
Alaimus & & Eudorylaimus & Pratylenchus \\
Bursilla & Prismatolaimus & Psilenchus \\
Cephalobus & & Tylencholaimus & Trichodorus \\
Cervidellus & & Tylenchorhynchus \\
Chiloplacus & & Tylenchus \\
Cruznema & & Xiphinema \\
Diploscapter & & \\
Eucephalobus & & \\
Heterocephalobus & & \\
Monhystera & & \\
Panagrolaimus & & \\
Plectus & & \\
Prismatolaimus & & \\
Rhabditis & & \\
\hline
\end{tabular}


the organic plots, but the effect was not statistically significant $(P=$ 0.08 ). Detection of other fungi was unrelated to management system (data not shown).

Population densities of nematode-trapping fungi. When the same species was found on dilution and sprinkle plates from the same sample, we used the larger estimate (from the dilution plates) to determine population density; we assumed that both techniques underestimate true population densities and that the larger estimate is more accurate. The most common fungi found were $A$. dactyloides, A. haptotyla, and A. thaumasia; population densities of other fungi usually were less than one propagule per gram of soil (data not shown). Densities of $A$. dactyloides were greater $(P=$ 0.03 ) in the organic than in the conventional plots (Fig. 3A); the same was true for $N$. leiosporus $(P<0.01)$, but densities seldom
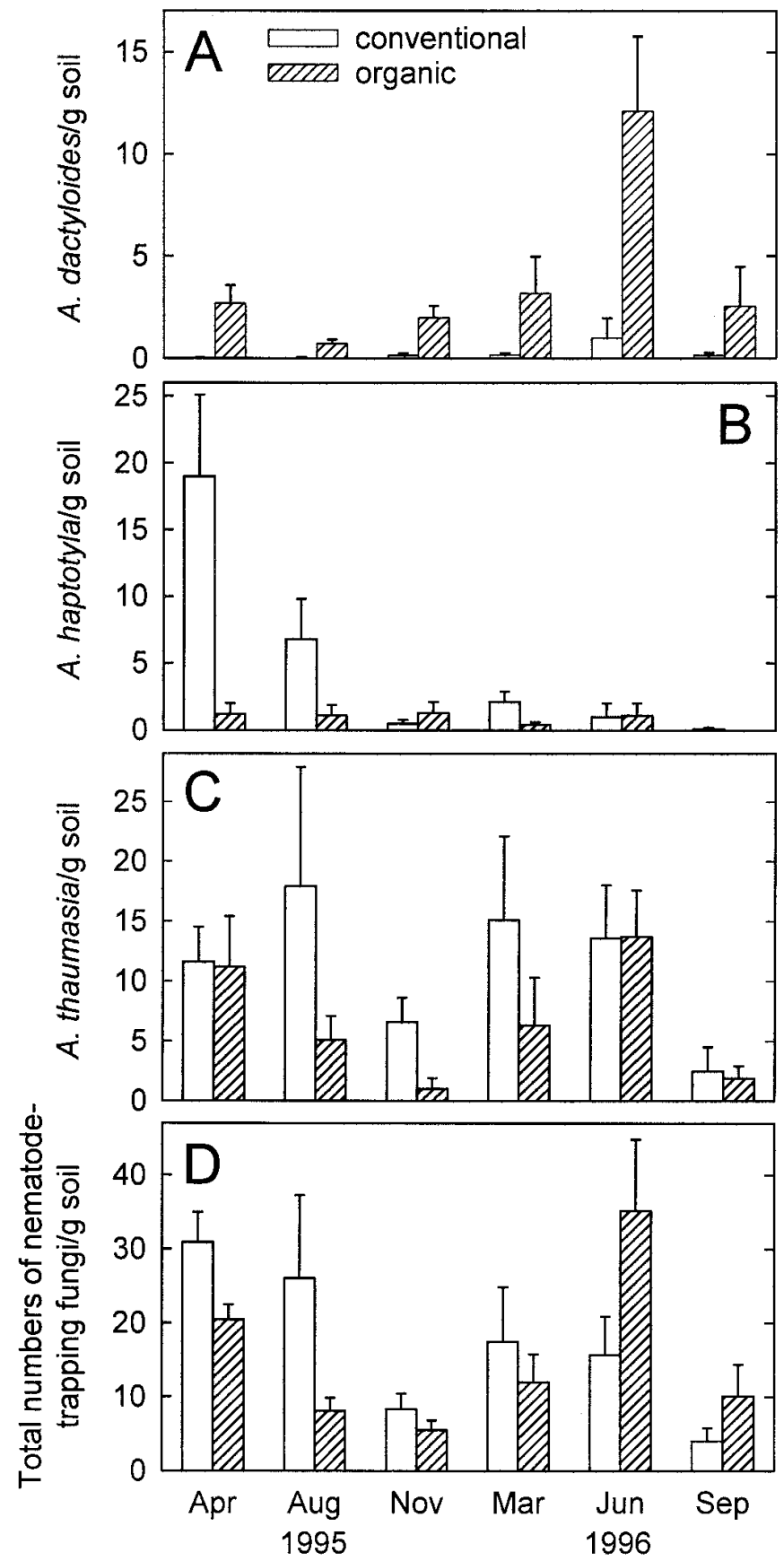

Fig. 3. Population densities of nematode-trapping fungi A, Arthrobotrys dactyloides; $\mathbf{B}$, A. haptotyla; $\mathbf{C}$, A. thaumasia; and $\mathbf{D}$, total trapping fungi in conventional and organic plots. Values are means plus the standard error of four replicate plots. exceeded one propagule per gram of soil (data not shown). Densities of A. haptotyla were greater in the conventional plots on the first sample date but did not differ between systems on other or overall dates $(P=0.09)$ (Fig. 3B). Densities of $A$. thaumasia were greater $(P=0.03)$ in the conventional than in the organic plots, although this was not apparent on all dates (Fig. 3C). Total density of nematode-trapping fungi was not affected by management system (Fig. 3D).

Nematodes. Both organic and conventional plots contained many different species of nematodes (Table 3). The number of bacterivorous nematodes was greater $(P=0.02)$ in organic plots than in conventional plots (Fig. 4A). The numbers of fungivorous, omnivorous, and plant-parasitic nematodes were unaffected by management system (Fig. 4B through D). Meloidogyne spp. were infrequently
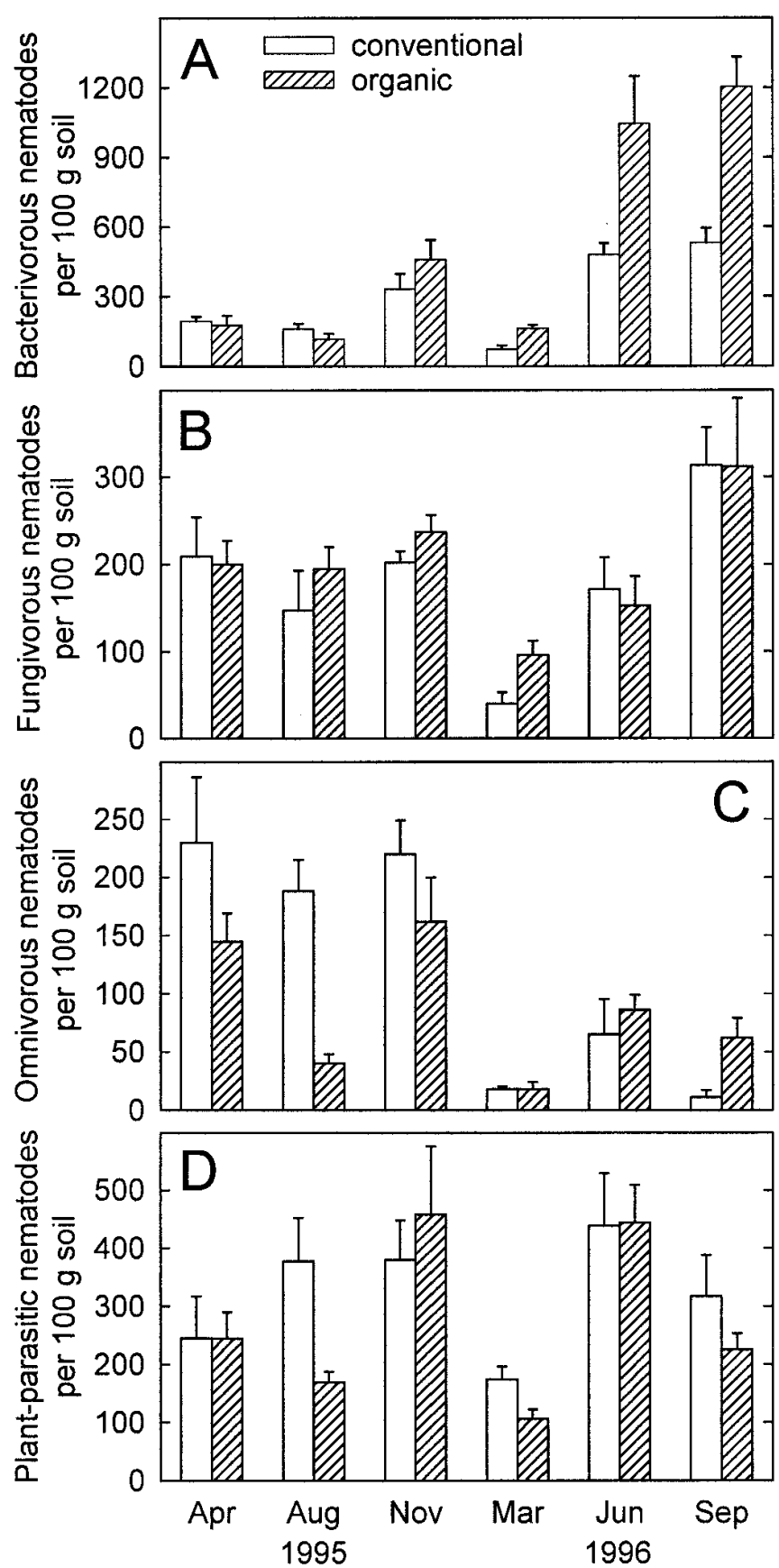

Fig. 4. Population densities of A, bacterivorous; $\mathbf{B}$, fungivorous; $\mathbf{C}$, omnivorous; and $\mathbf{D}$, plant-parasitic nematodes in conventional and organic plots. Values are means plus the standard error of four replicate plots. 
detected; the mean numbers per $100 \mathrm{~g}$ of soil were three in organic and one in conventional plots.

Bioassay for nematode suppression. The number of assay $M$. javanica in roots was less $(P<0.01)$ in nonheat-treated than in heat-treated soil for both cropping systems on all sampling dates, except April 1995; the overall mean number plus/minus standard error per replicate cup was $106 \pm 4$ in heat-treated soil and $57 \pm 3$ in nonheat-treated soil. Thus, suppression was substantial but was not significantly affected by management system (Fig. 5A). Suppression was not correlated with fungus density (total or by species).

To determine whether abiotic differences in soil from organic and conventional plots affected movement of $M$. javanica through soil and into roots, we compared the number of juveniles in roots per replicate cup in heat-treated organic soil $(101 \pm 6)$ versus heattreated conventional soil $(111 \pm 6)$. The difference was not statistically significant $(P=0.17)$.

Roots growing in nonheat-treated soil that was not artificially infested with $M$. javanica contained substantial numbers of endoparasitic nematodes (Fig. 5B). More than 90\% of these resident endoparasites were Pratylenchus spp., and fewer than $1 \%$ were Meloidogyne spp. Numbers of endoparasites in roots were highly variable and not significantly affected by management system.

Microbial biomass. Substrate-induced respiration was greater $(P<0.01)$ in organic than in conventional plots (Fig. 6). Moreover, the regression of root-knot suppression in the bioassay on substrate-induced respiration was significant (Fig. 7; $P<0.01, r^{2}=$ 0.21 ); addition of date and management as covariables increased the $r^{2}$ value to 0.94 . Substrate-induced respiration was not related to population densities of nematode-trapping fungi (data not shown).

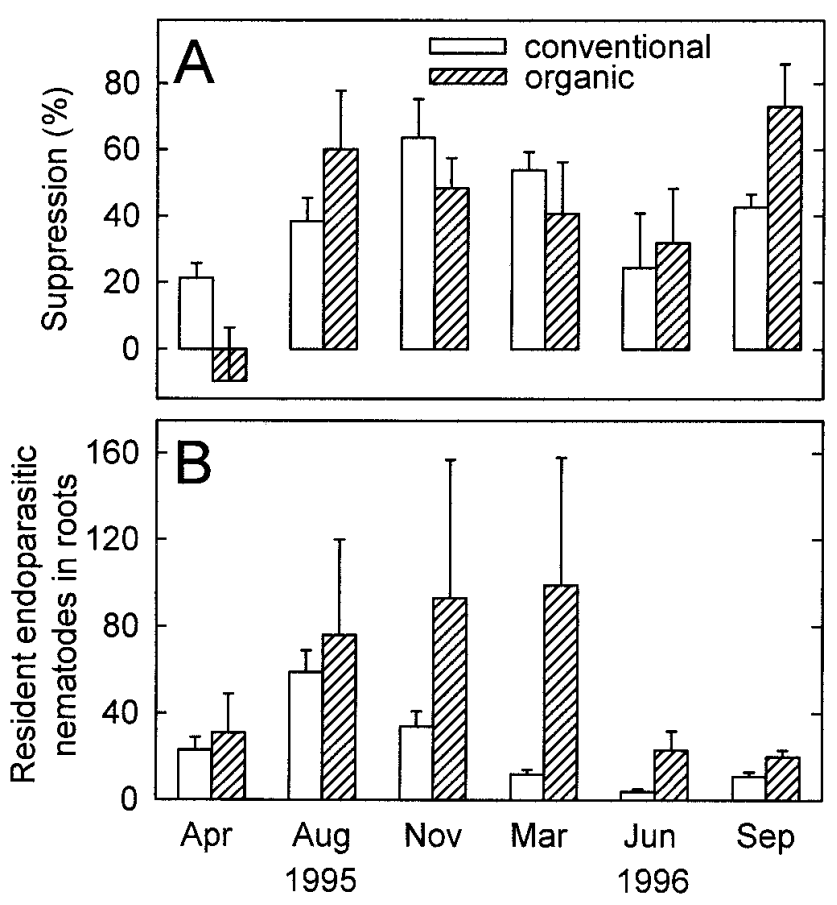

Fig. 5. Biotic suppression of root-knot nematodes (Meloidogyne javanica) and population density of resident endoparasitic nematodes in soil from conventional and organic plots. A, Biotic suppression. Heat-treated or nontreated soil was placed in cups, infested with $M$. javanica, and planted with cabbage. The number of $M$. javanica in roots was determined. Suppression $=(1-a / b)$ $\times 100$, where $a$ and $b$ refer to the number of $M$. javanica in roots growing in nontreated and heat-treated soil, respectively. B, Population density of resident endoparasitic nematodes. Nontreated soil was placed in cups and planted with cabbage (100 $\mathrm{cm}^{3}$ of soil and six seeds per cup). The number of nematodes in roots (mainly Pratylenchus sp.) was determined. Values are means plus the standard error of four replicates (data from two cups were averaged per replicate).
Water content of soil samples. Although the differences usually were minor, the water content of soil samples over all dates was greater $(P<0.01)$ in organic plots $(16.7 \pm 0.6 \%)$ than in conventional plots $(14.1 \pm 0.9 \%)$. Water content of soil used in the suppression bioassay ranged from 17 to $20 \%$. The following variables were not correlated with water content of soil samples: suppression in the bioassay, substrate-induced respiration, total population density of nematode-trapping fungi, number of $A$. dactyloides, and number of $A$. thaumasia. The number of $A$. haptotyla was positively correlated $(P=0.04)$ with water content of soil samples, but the relationship was not significant $(P>0.25)$ when data were examined separately by management system.

\section{DISCUSSION}

Researchers have proposed two models to explain how organic amendments might stimulate nematode-trapping fungi. The numerical response model presupposes that nematode-trapping fungi are obligate parasites in nature and depend on nematodes for carbon, nitrogen, and energy. According to this model, organic amendments stimulate sequential increases in numbers of bacteria, bacterivorous nematodes, and nematode-trapping fungi (20,24,31). In contrast, the supplemental nitrogen model presupposes that nematode-trapping fungi are facultative parasites. By obtaining nitrogen from nematodes, the fungi can compete for the carbon and energy bound in carbon-rich, nitrogen-poor plant litter $(2,8,41)$. The current study does not address which model is correct but does address whether organic amendments actually stimulate nematodetrapping fungi in agricultural fields. We begin with this simpler question because the responses of nematode-trapping fungi to organic amendments seldom have been quantified.

In the SAFS Project at the University of California at Davis, the organically managed plots receive much greater organic matter inputs than do the conventionally managed plots. Consequently, microbial biomass and number of bacterivorous nematodes are greater in the organic plots, as documented in previous reports $(15,18)$ and in the current study. We, therefore, anticipated finding a greater number of nematode-trapping fungi in the organic plots, regardless of which model correctly describes the relationship between the fungi, nematodes, and organic matter. Our expectation was partially met. A. dactyloides and $N$. leiosporus were detected more frequently and in greater numbers in the organic than in the conventional plots. A. dactyloides, which produces constricting rings, is a common fungus and has been detected more frequently in soils amended with organic matter than in nonamended soils in previous studies $(33,34)$. Other species with constricting rings also have been detected frequently in soils with high levels of organic matter $(16,17)$. N. leiosporus produces adhesive glandular cells and

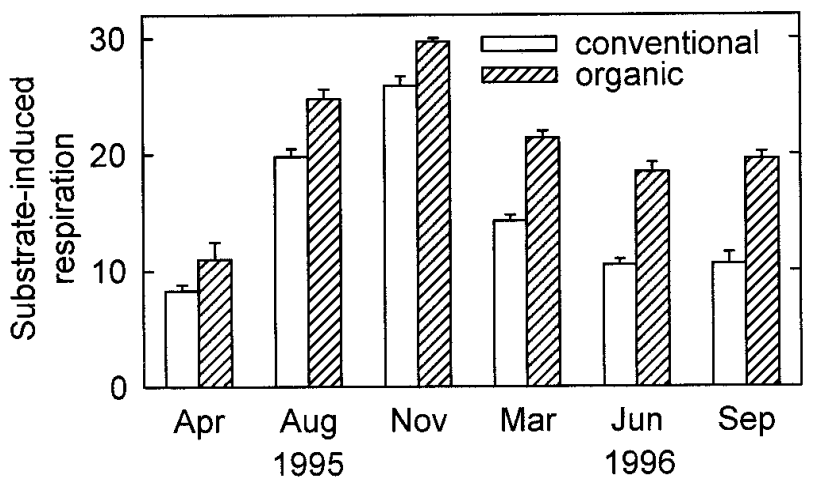

Fig. 6. Substrate-induced respiration (micrograms of $\mathrm{CO}_{2}$ per gram of soil per hour) in soil from conventional and organic plots. Values are the means plus the standard error of four replicates. 
often is detected in substrates with elevated organic matter content, such as barnyard soil and dung (42).

Unlike A. dactyloides and $N$. leiosporus, A. thaumasia produces adhesive networks and was detected less often and in smaller numbers in organic plots. To explain this, we might state that the relationship between organic matter, nematodes, and nematodetrapping fungi apparently differs between fungi with adhesive networks and fungi with constricting rings, as indicated in ecological classifications $(7,25)$. According to these classifications, the ring-forming species seem to be obligate parasites and, therefore, may follow the numerical response model, whereas the network formers may be more saprophytic and follow the supplemental nitrogen model. While not explaining why some fungi were stimulated and others suppressed in organic plots, the classifications appear to provide a basis for the difference. The pattern blurs, however, when A. haptotyla is considered. A. haptotyla produces adhesive knobs and is grouped with A. dactyloides in ecological classifications $(7,25)$. Consequently, it should behave more like $A$. dactyloides than like A. thaumasia. This was not the case in this study, however; A. haptotyla tended to be more common and numerous in conventional than in organic plots.

In addition to predicting that nematode-trapping fungi would be more abundant in organic plots, we also hypothesized that suppressiveness would correlate with the density of nematode-trapping fungi and that organic plots would be more suppressive to root-knot nematodes than conventional plots. The data did not support either of these hypotheses. As in a previous study (23), suppression of the root-knot nematode ( $M$. javanica), which is highly susceptible to many nematode-trapping fungi, including $A$. dactyloides, A. haptotyla, and A. thaumasia (22; B. A. Jaffee, unpublished data), was unrelated to fungus numbers. We tentatively conclude that suppression was not caused by nematodetrapping fungi. We must be tentative because our assessment of nematode-trapping fungi population densities provides incomplete information on activity and numbers in soil $(10,23)$. For example, our methods may have substantially underestimated the number of N. leiosporus (42).

Other limitations of this study include an inability to detect transient increases in fungi (6) because sampling was infrequent; an inability to detect slow, long-term changes in fungi because sampling was short term; an inability to separate the effects of crop and year (the organic effect seems to have been stronger in 1996, when tomato was grown and manure was added to organic plots); insufficient data on fungivores and other enemies of fungi in the silty loam; lack of information on the susceptibility of the nematodes, especially bacterivorous species, to the fungi; and lack

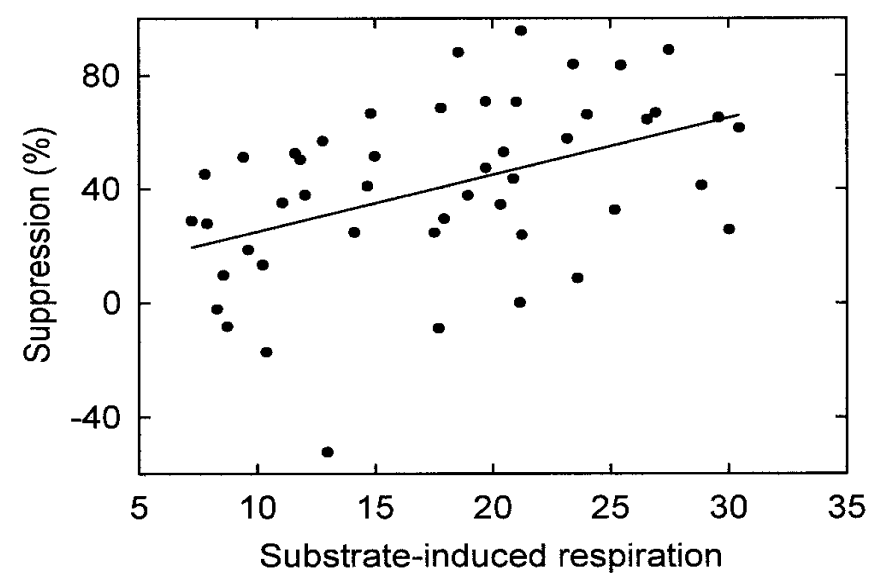

Fig. 7. Relationship between the biotic suppression of the root-knot nematode (Meloidogyne javanica) and substrate-induced respiration. Each value is from one replicate $(n=48)$. of data on other enemies of nematodes in the silty loam. In addition, the macroporosity of the silty loam probably is suboptimal for root-knot nematodes.

Although unrelated to population densities of nematode-trapping fungi and cropping system, suppression was positively but weakly correlated with microbial biomass, as measured by substrateinduced respiration. This correlation seems unreasonable at first consideration, because substrate-induced respiration was greater in organic than in conventional plots but suppression was not. However, the independent variable in the regression of suppression on respiration included a wide range and a large number of values, whereas the independent variable in the analysis of variance was categorical (conventional versus organic management); the regression, therefore, was more sensitive than the analysis of variance. Perhaps with substantially greater replication, we would have documented greater suppressiveness in the organic than in the conventional plots. The basis for the relationship between substrate-induced respiration and suppression is unknown.

\section{ACKNOWLEDGMENTS}

This research was partially funded by a grant from the University of California Sustainable Agriculture and Education Program. S. Lau, A. Muldoon, L. Timm, D. Pearson, and H. van der Meulen provided technical assistance; N. Willits provided statistical advice; and Rogers Seed Co., Boise, ID, provided seed. We thank H.-B. Jansson, L. Persmark, and D. Rizzo for comments on an earlier version of the manuscript.

\section{LITERATURE CITED}

1. Barron, G. L. 1977. The Nematode-Destroying Fungi. Canadian Biological Publications, Guelph, ON, Canada.

2. Barron, G. L., and Dierkes, Y. 1977. Nematophagous fungi: Hohenbuehelia, the perfect state of Nematoctonus. Can. J. Bot. 55:3054-3062.

3. Bouwman, L. A., Hoenderboom, G. H. J., van der Maas, K. J., and de Ruiter, P. C. 1996. Effects of nematophagous fungi on numbers and death rates of bacterivorous nematodes in arable soil. J. Nematol. 28:2635 .

4. Byrd, D. W., Jr., Barker, K. R., Ferris, H., Nusbaum, C. J., Griffin, W. E., Small, R. H., and Stone, C. A. 1976. Two semi-automatic elutriators for extracting nematodes and certain fungi from soil. J. Nematol. 8:206-212.

5. Byrd D. W., Jr., Kirkpatrick, T., and Barker, K. R. 1983. An improved technique for clearing and staining plant tissues for detection of nematodes. J. Nematol. 15:142-143.

6. Cooke, R. C. 1962. Behavior of nematode-trapping fungi during decomposition of organic matter in soil. Trans. Br. Mycol. Soc. 45:314320.

7. Cooke, R. C. 1963. Ecological characteristics of nematode-trapping Hyphomycetes. I. Preliminary studies. Ann. Appl. Biol. 52:431-437.

8. Cooke, R. C. 1968. Relationships between nematode-destroying fungi and soil-borne phytonematodes. Phytopathology 58:909-913.

9. Cooke, R. C., and Godfrey, B. E. S. 1964. A key to the nematode-destroying fungi. Trans. Br. Mycol. Soc. 47:61-74.

10. Dackman C., Jansson, H.-B., and Nordbring-Hertz, B. 1992. Nematophagous fungi and their activities in soil. Pages 95-130 in: Soil Biochemistry. Vol. 7. G. Stotzky and J. M. Bollag, eds. Marcel Dekker, New York.

11. Dackman, C., Olsson, S., Jansson, H.-B., Lundgren, B., and NordbringHertz, B. 1987. Quantification of predatory and endoparasitic nematophagous fungi in soil. Microb. Ecol. 13:89-93.

12. Duddington, C. L. 1957. The Friendly Fungi. Faber and Faber, London.

13. Eren, J., and Pramer, D. 1965. The most probable number of nematodetrapping fungi in soil. Soil Sci. 99:285.

14. Eren, J., and Pramer, D. 1978. Growth and activity of the nematodetrapping fungus Arthrobotrys conoides in soil. Pages 121-127 in: Microbial Ecology. M. W. Loutit and J. A. R. Miles, eds. Springer-Verlag, Berlin.

15. Ferris, H., Venette, R. C., and Lau, S. S. 1996. Dynamics of nematode communities in tomatoes grown in conventional and organic farming systems, and their impact on soil fertility. Appl. Soil Ecol. 3:161-175.

16. Gray, N. F. 1985. Ecology of nematophagous fungi: Effect of soil moisture, organic matter, $\mathrm{pH}$ and nematode density on distribution. Soil Biol. Biochem. 17:449-507.

17. Gray, N. F., and Bailey, F. 1985. Ecology of nematophagous fungi: Vertical distribution in a deciduous woodland. Plant Soil 86:217-223. 
18. Gunapala, N., and Scow, K. M. Dynamics of soil microbial biomass and activity in conventional and organic farming systems. Soil Biol. Biochem. In press.

19. Hoffmann-Hergarten, S., and Sikora, R. A. 1993. Untersuchung zur Steigerung der Wirkung nematodenfangender Pilze gegen den Heterodera schachtii-Frühbefall durch organische Dünger. Z. Pflanzenkr. Pflanzenschutz 100:170-175.

20. Jaffee, B. A. 1993. Density-dependent parasitism in biological control of soil-borne insects, nematodes, fungi and bacteria. Biocontrol Sci. Technol. 3:235-246.

21. Jaffee, B. A., Ferris, H., Stapleton, J. J., Norton, M. V. K., and Muldoon, A. E. 1994. Parasitism of nematodes by the fungus Hirsutella rhossiliensis as affected by certain organic amendments. J. Nematol. 26:152161.

22. Jaffee, B. A., and Muldoon, A. E. 1995. Susceptibility of root-knot and cyst nematodes to the nematode-trapping fungi Monacrosporium ellipsosporum and M. cionopagum. Soil Biol. Biochem. 27:1083-1090.

23. Jaffee, B. A., Strong, D. R., and Muldoon, A. E. 1996. Nematodetrapping fungi of a natural shrubland: Tests for food chain involvement. Mycologia 88:554-564.

24. Jaffee, B. A., Tedford, E. C., and Muldoon, A. E. 1993. Tests for densitydependent parasitism of nematodes by trapping and endoparasitic fungi. Biol. Control 3:329-336.

25. Jansson, H.-B., and Nordbring-Hertz, B. 1980. Interactions between nematophagous fungi and plant-parasitic nematodes: Attraction, induction of trap formation and capture. Nematologica 26:383-389.

26. Jenkins, W. R. 1964. A rapid centrifugal-flotation technique for separating nematodes from soil. Plant Dis. Rep. 48:692.

27. Kaya, H. K., and Stock, S. P. 1997. Techniques in insect nematology. Pages 281-324 in: Manual of Techniques in Insect Pathology. L. Lacey, ed. Academic Press, San Diego, CA.

28. Klee, A. 1993. A computer program for the determination of most probable number and its confidence limits. J. Microbiol. Methods 18:91-98.

29. Lambert, K. N., Tedford, E. C., Caswell, E. P., and Williamson, V. M. 1992. A system for continuous production of root-knot nematode juveniles in hydroponic culture. Phytopathology 82:512-515.

30. Lanini, W. T., Zalom, F., Marois, J., and Ferris, H. 1994. Researchers find short-term insect problems, long-term weed problems. Calif. Agric. 48:27-33.

31. Linford, M. B., Yap, F., and Oliveira, J. M. 1938. Reduction of soil populations of the root-knot nematode during decomposition of organic matter. Soil Sci. 45:127-141.

32. Mankau, R. 1962. The effect of some organic additives upon a soil nematode population and associated natural enemies. Nematologica 7:65-73.

33. Mankau, R. 1968. Reduction of root-knot disease with organic amendments under semifield conditions. Plant Dis. Rep. 52:315-319.

34. Mankau, R., and Minteer, R. J. 1962. Reduction of soil populations of the citrus nematode by addition of organic materials. Plant Dis. Rep. 46: 375-378.

35. Persmark, L. 1997. Ecology of nematophagous fungi in agricultural soils. Ph.D. thesis. Lund University, Lund, Sweden.

36. Persmark, L., Banck, A., and Jansson, H.-B. 1996. Population dynamics of nematophagous fungi and nematodes in an arable soil: Vertical and seasonal fluctuations. Soil Biol. Biochem. 28:1005-1014.

37. Persmark, L., and Jansson, H.-B. 1997. Nematophagous fungi in the rhizosphere of agricultural crops. FEMS Microbiol. Ecol. 22:303-312.

38. Scow, K. M., Somasco, O., Gunapala, N., Lau, S., Venette, R., Ferris, H., Miller, R., and Shennan, C. 1994. Transition from conventional and lowinput agriculture changes soil fertility and biology. Calif. Agric. 48:20-26.

39. Temple, S. R., Friedman, D. B., Somasco, O., Ferris, H., Scow, K. M., and Klonsky, K. 1994. An interdisciplinary, experiment station-based participatory comparison of alternative crop management systems for California's Sacramento Valley. Am. J. Altern. Agric. 9:64-71.

40. Temple, S. R., Somasco, O. A., Kirk, M., and Friedman, D. 1994. Conventional, low-input, and organic farming systems compared. Calif. Agric. 48:14-19.

41. Thorn, R. G., and Barron, G. L. 1984. Carnivorous mushrooms. Science 224:76-78

42. Thorn, R. G., and Barron, G. L. 1986. Nematoctonus and the tribe Resupinateae in Ontario, Canada. Mycotaxon 25:321-453.

43. van den Boogert, P. H. J. F., Velvis, H., Ettema, C. H., and Bouwman, L. A. 1994. The role of organic matter in the population dynamics of the endoparasitic nematophagous fungus Drechmeria coniospora in microcosms. Nematologica 40:249-257.

44. West, A. W., and Sparling, G. P. 1986. Modifications to the substrateinduced respiration method to permit measurement of microbial biomass in soils of differing water contents. J. Microbiol. Meth. 5:177-189.

45. Woomer, P. L. 1994. Most probable number counts. Pages 59-79 in: Methods of Soil Analysis. Part 2: Microbiological and Biochemical Properties. R. W. Weaver, S. Angle, P. Bottomley, D. Bezdicek, S. Smith, A. Tabatabai, and A. Wollum, eds. SSSA Book Series, No. 5. Soil Science Society of America, Madison, WI. 